\title{
Medication errors in a neonatal intensive care unit
}

\author{
Renata Bandeira de Melo Escovedo Lerner, ${ }^{1}$ Manoel de Carvalho, ${ }^{2}$ \\ Alan Araújo Vieira, ${ }^{3}$ Jose Maria de Andrade Lopes, ${ }^{4}$ \\ Maria Elisabeth Lopes Moreira ${ }^{5}$
}

\begin{abstract}
Objective: To determine the incidence and type of medical errors in a newborn intensive care unit and the relationship between the error and the patient's clinical status.

Methods: We reviewed the medical charts, during the first 7 days of hospitalization, of all high-risk newborn infants admitted for a period of 3 months.

Results: Seventy-three patients were admitted during the study period. Their mean birth weight was $2,140 \mathrm{~g}$ (640-5,020 g) and mean gestational age was 34 weeks (25-40 weeks). Of 73 medical charts analyzed, 40 (55\%) had one or more errors. A total of 365 days of hospitalization was analyzed and 95 medical errors were detected (one error per 3.9 days of hospitalization). The most frequent error was associated with medication use ( $84.2 \%)$. Use of therapeutic procedures (drugs, phototherapy, etc.) without proper prescription in the patient's chart (commission error) accounted for $7.4 \%$ of the errors, and incidence of omission errors was $8.4 \%$. Incidence of medical errors was significantly higher in newborn infants with lower gestational age.
\end{abstract}

Conclusions: Incidence of errors in the care of high-risk newborn infants is elevated. Strategies to improve education of health professionals involved in the care and development of local culture by disseminating clear, accessible algorithms to guide behavior when errors occur must be encouraged.

J Pediatr (Rio J). 2008;84(2):166-170: Medical errors, neonatal unit, newborn infant.

\section{Introduction}

Medical errors, adverse events and patient safety are outstanding themes in medical literature throughout the world because these errors may harm patients and their families, as well as increase the duration of hospital stay and its costs. A recent study showed that 3-4\% of hospitalized patients are harmed by the care that was supposed to assist them. It is estimate that 44,000 to 98,000 Americans die each year due to medical errors. This is more than the incidence of death caused by car accidents, AIDS, breast cancer or labor-related casualties. $^{1}$

Several studies indicate that patients who suffer from complex medical problems and thus require multiple medical interventions are more exposed to errors during their hospital stay. ${ }^{2,3}$

Newborn infants admitted to intensive care units are particularly susceptible to medical errors. This is due to the fact that, being at risk, they require the application of high technology, together with the need for individualized medical prescription, based on body weight and gestational age. ${ }^{4,5}$

The purpose of this study was to determine the frequency of medical errors in a newborn intensive care unit (NICU) and to relate these errors with clinical characteristics of the patients, the complexity of care provided and the availability of human and technological resources.

1. Médica. Mestre, Instituto Fernandes Figueira, Fundação Oswaldo Cruz (Fiocruz), Rio de Janeiro, RJ, Brazil.

2. Médico. Docente, Pós-Graduação em Saúde da Criança e da Mulher, Instituto Fernandes Figueira, Fiocruz, Rio de Janeiro, RJ, Brazil.

3. Doutor. Pós-Graduação em Saúde da Criança e da Mulher, Instituto Fernandes Figueira, Fiocruz, Rio de Janeiro, RJ, Brazil.

4. Médico. Pesquisador, Instituto Fernandes Figueira, Fiocruz, Rio de Janeiro, RJ, Brazil.

5. Médica. Docente, Pós-Graduação em Saúde da Criança e da Mulher, Instituto Fernandes Figueira, Fiocruz, Rio de Janeiro, RJ, Brazil.

No conflicts of interest declared concerning the publication of this article.

Suggested citation: Lerner RB, de Carvalho M, Vieira AA, Lopes JM, Moreira ME. Medication errors in a neonatal intensive care unit. J Pediatr (Rio J). 2008;84(2):166-170.

Manuscript received Oct 02 2007, accepted for publication Nov 102007.

doi:10.2223/JPED.1757 


\section{Methods}

We conducted a cohort-type study in a NICU, which has 12 intensive care and 10 intermediate care beds. Our NICU is located in a maternity hospital that is the referral center for high-risk pregnancies in the city of Rio de Janeiro, Brazil. Medical care and prescriptions are provided by staff neonatologists, fellows and pediatric residents. The medication is prepared in the pharmacy and delivered individually to every patient admitted to the NICU. All medications are administered by the nurse staff. The study was a retrospective analysis of medical charts of all newborn infants admitted to our NICU during a period of 3 consecutive months from birth to the seventh day of life. To estimate the relationship between patient/nurse ratio and number of errors, we observed patient/nurse ratio, occupancy rate and number of errors per day during 90 consecutive days. All charts were analyzed by the same investigator. In case of newborn death or transfer to another unit, we considered the number of days the patient actually stayed in our NICU.

Occurrence of errors or failures in the process of caring for the patient was evaluated through a careful analysis of the infant's record and medical prescriptions. Errors analyzed were those found in the patient's record. The researcher simply registered the errors but did not interpret the conduct adopted by the health professional involved in the process. We considered an error in the assistance process any error committed by a health professional involved in the patient's care during hospitalization. These errors were classified as follows.

Medication error. Includes any error, large or small, at any point in the medication system from the time the drug is ordered until the patient receives it. This differs from some prior definitions that considered only deviations from the physician's orders. ${ }^{2}$ This error was classified as follows: a) incorrect speed of intravenous fluids/drugs infusion - more or less than $10 \%$ of the prescribed rate; b) omission of dosage; c) incorrect schedule; d) inappropriate dosage; e) unauthorized drug (drugs not allowed for use in newborn infants); f) incorrect administration of drug. ${ }^{6}$ To check the correct dose of any prescribed medication, the researcher recalculated all dosages using the Neofax as a standard guideline. $^{7}$

Omission error. Characterized by a failure of action such as missed diagnosis, delayed evaluation or failure to prescribe a required drug treatment. For example: hypoglycemia documented and not treated. ${ }^{8}$

Commission error. Characterized by an incorrect action, such as administering the wrong drug to the wrong patient at a wrong time. Noncompliance with medical order prescribed for the patient. For example: phototherapy was prescribed for a newborn infant but was not administered.
To evaluate the degree of required use of technology by a newborn infant (an indirect measure of the severity of his/ her clinical condition) we used the Neonatal Therapeutic Intervention Scoring System (NTISS). ${ }^{9}$ This instrument was applied daily by the researcher during hospitalization of the patients included in the study. The NTISS was empirically divided into clinical subscores. Each technology and therapy used for the patient receives a specific punctuation. The daily NTISS score is computed as the arithmetic sum of therapy points received by a patient in a 24-hour period. For mutually exclusive items, only the most heavily weighted item is included in this computation. ${ }^{9}$ With the purpose of measuring the mortality risk of newborns admitted to the NICU within the first 12 hours, we used the Score for Neonatal Acute Physiology Perinatal Extension (SNAPPE) score. ${ }^{10}$ This score is simple, rapid, and accurate and can be applied to babies of all birth weights as an admission score in the NICU. It is not designed as a sequential score for use over several days.

The variables analyzed in our study were error frequency, type of error, birth weight (g), gestational age (weeks), and NTISS. We also analyzed other variables that might be related to error, such as number of nursing personnel on duty at the NICU, number of hospitalized patients, occupancy rate (total number of beds allocated in the NICU/number of patients in the NICU), relationship between the number of newborn infants at the NICU and nursing staff and days of hospitalization. We also recorded when the error occurred (day/night shift).

Statistical analyses used ANOVA for continuous variables and chi-square for categorical variables. To analyze scores (NTISS and SNAPPE) we used the Wilcoxon test and nonparametric Spearman's rank correlation test and Kendall's rank correlation test in SPSS software 13.0 was used to perform correlation analyses between variables (patient/nurse ratio and number of errors).

The neonatal department and the ethics committee of Instituto Fernandes Figueira approved this research protocol. Since this study involved only analysis of records, the institutional review board waived the need for consent.

\section{Results}

Seventy-six patients were admitted to the NICU during the study period. Three medical records of patients were not located. The final sample of the study comprised the medical records of 73 newborn infants (Table 1 ).

Among the 73 patients' records analyzed, 40 (54\%) reveled one or more errors. Considering the length of stay as 5 days, the number of days analyzed was 365 ( $5 \times 73$ ). During this period, 95 errors were detected, the equivalent to one error per 3.9 days of hospitalization. Among the 40 patients in whom an error was detected, the average number of errors per patient was two (one to nine). Medication error was the most common error recorded (84.2\%), followed by omission 
Table 1 - Demographic characteristics of the study population (73 patients)

\begin{tabular}{lcc}
\hline & Mean \pm SD & Range \\
\hline Birth weight $(\mathrm{g})^{*}$ & $2,155 \pm 890$ & $640-5,020$ \\
Gestational age (weeks)* & $34 \pm 4$ & $25-40$ \\
NTISS (median) & 11 & $1-22$ \\
Length of stay NICU (days)* & $5 \pm 2$ & $1-7$ \\
\hline
\end{tabular}

NICU = newborn intensive care unit; NTISS = Neonatal Therapeutic Intervention Scoring System; SD = standard deviation.

$*$ Mean \pm standard deviation.

(8.4\%) and commission error (7.4\%). Among medication errors, the most frequent was that caused by incorrect programming of infusion pumps leading to an inadequate administration of intravenous fluids ( $88 \%)$. Incorrect dosage of drugs accounted for $11.8 \%$ of the error.

Newborn infants in whom an error was detected were significantly more premature, had lower birth weight and remained longer in the NICU than those in whom error in the assistance process was not found (Table 2). Severity of the newborn clinical condition (SNAPPE) and index of technology use (NTISS) were not different between both groups.

Incidence of medical errors was significantly greater during day time than during night time ( $64 \%$ vs. $34 \%$ ), in patients less than 32 weeks gestational age and in those weighing less than $1,500 \mathrm{~g}$.

Average number of nurses per shift was $2.4 \pm 1$ (1-5) and average daily number of newborn infants admitted in the NICU was $13 \pm 1.8$ (6-18). Occupancy rate during the study period varied from 50 to $150 \%$ (mean $108 \%$ ). In general, each nurse took care of 2.28 newborn infants. There was no association between occurrence of errors and total number of nurse staff neither a relationship between number of newborns/nursing personnel and daily occupation rate of the NICU. Using nonparametric correlation test of Kendal's and Spearman in SPSS software 13.0, there was no significant correlation between number of errors and patient/nurse ratio $(r=0.147)$.

\section{Discussion}

Although newspaper and television stories of catastrophic injuries occurring at the hands of clinicians spotlight the problem of medical errors, they provide little insight into its nature or magnitude. ${ }^{11}$ Clinicians, patients and policy makers may underestimate magnitude of risk and extent of harm. ${ }^{11}$

Occurrence of medical errors in hospitalized patients is much higher than previously thought. Medical errors increase costs and length of stay, as well as morbidity and mortality. ${ }^{12}$

Although the issue of medical error is important, there are many difficulties in systematically studying it. One of the greatest challenges faced by studies focused on this problem is that errors are usually underreported, as most of the analysis conducted is based on voluntary and anonymous notifications by health professionals. ${ }^{3}$ There is also no consensus to define medical error. Different terminologies are used to characterize adverse events, adverse drug events and medical error and several methods have been proposed to identify errors or adverse events. ${ }^{13,14}$

Incidence and nature of medication errors have also been revised, and Chedoe et al. found 11 original studies in English

Table 2 - Characteristics of newborn infants according to occurrence of errors

\begin{tabular}{lccc}
\hline & $\begin{array}{c}\text { Medical error not found } \\
(\mathbf{n}=\mathbf{3 3})\end{array}$ & $\begin{array}{c}\text { Medical error found } \\
(\mathbf{n}=\mathbf{4 0})\end{array}$ & $\mathbf{p}$ \\
\hline Birth weight $(\mathrm{g})^{*^{+}}$ & $2,415 \pm 905$ & $1,940 \pm 825^{*}$ & 0.017 \\
Gestational age (weeks) $*^{+}$ & $35 \pm 3$ & $33 \pm 4 *$ & 0.021 \\
Length of stay (days) $*^{+}$ & $4 \pm 2$ & $5 \pm 2 *$ & 0.000 \\
NTISS median (min-max) & $8(5-17)$ & $7(6-22)$ & 0.146 \\
SNAPPE median (min-max) & $0(0-50)$ & $0(0-49)$ & 0.461 \\
\hline
\end{tabular}

NTISS = Neonatal Therapeutic Intervention Scoring System; SNAPPE = Score for Neonatal Acute Physiology Perinatal Extension.

* ANOVA.

+ Mean \pm standard deviation.

* Wilcoxon test. 
about frequency of medication errors in the NICU. In their revision, medication error rates varied widely between studies, partly due to differences in the definition of an error and the rigor of the method used to identify medication errors. The highest rate was 5.5 medication errors per 100 prescriptions. Furthermore, they had problems to compare incidences because medication error rates between studies were calculated differently. ${ }^{15}$

Analysis of 73 medical records of patients admitted to our NICU shows that $40(54.8 \%)$ had been subjected to one or more errors during the first week of hospitalization. The most frequent error was related to incorrect infusion of drugs and intravenous fluids, due to mismanagement of infusion pumps (all infusion pumps used in our NICU are periodically tested by our clinical engineering department). Similar results have been published in the medical literature. ${ }^{4,16,17}$ Since this study was based on a retrospective analysis of the patients' medical charts, it was not possible to associate the error (when it occurred) and its effect on the patient's clinical condition.

Our results showed that errors were significantly more frequent in newborn infants with lower birth weight, lower gestational age and longer NICU stay. These results are similar to those found by Slonin et al., ${ }^{3}$ Vincer et al., ${ }^{4}$ and others ${ }^{17,18}$ that demonstrated a higher incidence of errors in patients that required ventilatory assistance.

The NTISS was developed and validated as a measure of neonatal therapeutic intensity. This scale is easily abstracted from medical records, is highly internally consistent and provides information beyond that available from traditional risk determinants. Therapy-based severity of illness assessment indexes, such as NTISS, quantify illness severity by tabulating intensity of therapies received by a patient. It must be emphasized that they rely on the assumption that, given similar philosophies or styles of care, intensity of therapy is an indirect measure of illness severity. High-risk patients, requiring greater use of technology are more susceptible to medical errors.11 However, in our study there was no correlation between higher use of technology and occurrence of medical errors. This is possibly due to the fact that we chose to study the first 7 days of the infant's life, a period when all patients were in a more serious clinical condition and, therefore, required extensive use of technology.

Workload of health professionals and daily occupation rate of the NICU are relevant factors in the genesis of errors. ${ }^{16-20}$ It is believed that a heavy workload, together with tiredness and sleep deprivation, reduce the attention span and the ability of health professionals, thus facilitating occurrence of errors. ${ }^{18-20}$ Although our daily occupation rate was high, our study did not show a relationship between occurrence of errors and number of nursing professionals on duty or patients/ nursing ratio. A research conducted by the Vermont Oxford
Network demonstrated that only $2 \%$ of medical errors occurring in a NICU were associated with an inadequate relation between number of patients/nursing staff. ${ }^{16}$

There is much debate in the literature concerning the relationship between NICU occupation rate and incidence of errors. ${ }^{16}$ Overcrowding might give rise to errors due to increased workload and thus generate more stress in the professional involved in the care. On the other hand, a NICU with a low occupation rate may contribute towards reducing the attention span of health professionals. ${ }^{16}$

Our study presents limitations that should be considered when interpreting our results. The chart review design allowed that only those errors that could be picked up by the researcher were included in our analysis. However, in a busy working place such as NICU, several errors may go undetected even though all drugs are correctly prescribed. Nevertheless, this type of research should be encouraged in all units engaged in the care of high-risk patients. They are an important tool to review processes, implement strategies and increase registration and notification of errors and adverse events. ${ }^{11,14,19,20}$

\section{References}

1. Kohn LT, Corrigan JM, Donaldson MS. To err is human: building a safer health system. Washington: National Academies; 2000.

2. Cimino MA, Kirschbaum MS, Brodsky L, Shaha SH; Child Health Accountability Initiative. Assessing medication prescribing errors in pediatric intensive care units. Pediatr Crit Care Med. 2004;5: 124-32.

3. Slonim AD, LaFleur BJ, Ahmed W, Joseph JG. Hospital-reported medical errors in children. Pediatrics. 2003;111:617-21.

4. Vincer MJ, Murray JM, Yuill A, Allen AC, Evans JR, Stinson DA. Drug errors and incidents in a neonatal intensive care unit. $A$ quality assurance activity. Am J Dis Child. 1989;143:737-40.

5. Lehmann CU, Kim GR. Prevention of medication errors. Clin Perinatol. 2005;32:107-23.

6. American Society of Hospital Pharmacists. ASHP guidelines on preventing medical errors in hospitals. Am J Hosp Pharm. 1993; 50:305-14.

7. Young TE, Mangum B. Neofax $®$ : a manual of drugs used in neonatal care. 18th ed. Raleigh: Acorn Publishing; 2005.

8. Weingart SN, Wilson RM, Gibberd RW, Harrison B. Epidemiology of medical error. BMJ. 2000;320:774-7.

9. Mendes I, de Carvalho M, Almeida RT, Moreira ME. Use of technology as an evaluation tool of clinical care in preterm newborns. J Pediatr (Rio J). 2006;82:371-6.

10. Richardson DK, Corcoran JD, Escobar GJ, Lee SK. SNAP-II and SNAPPE-II: Simplified newborn illness severity and mortality risk scores. J Pediatr. 2001;138:92-100.

11. Weingart SN, Pagovich O, Sands DZ, Li JM, Aronson MD, Davis RB, et al. What can hospitalized patients tell us about adverse events? Learning from patient-reported incidents. J Gen Intern Med. 2005;20:830-6. 
12. Brennan TA, Leape LL, Laird NM, Hebert L, Localio AR, Lawthers AG et al. Incidence of adverse events and negligence in hospitalized patients: results of the Harvard Medical Practice Study I. N Engl J Med. 1991;324:370-6.

13. Grant MJ, Larsen GY. Effect of an anonymous reporting system on near-miss and harmful medical error reporting in a pediatric intensive care unit. J Nurs Care Qual. 2007;22:213-21.

14. Sharek PJ, Horbar JD, Mason W, Bisarya H, Thurm CW, Suresh G, et al. Adverse events in the neonatal intensive care unit: development, testing, and findings of an NICU-focused trigger tool to identify harm in North American NICUs. Pediatrics. 2006;118:1332-40.

15. Chedoe I, Molendijk HA, Dittrich ST, Jansman FG, Harting JW, Brouwers JR, et al. Incidence and nature of medication errors in neonatal intensive care with strategies to improve safety: a review of the current literature. Drug Saf. 2007;30:503-13.

16. Suresh G, Horbar JD, Plsek P, Gray J, Edwards WH, Shiono PH, et al. Voluntary anonymous reporting of medicals errors for neonatal intensive care. Pediatrics. 2004;113:1609-18.
17. Ross LM, Wallace J, Paton JY. Medication errors in a pediatric teaching hospital in the UK: five years operational experience. Arch Dis Child. 2000;83:492-7.

18. Gaba DM, Howard SK. Patient safety: fatigue among clinicians and the safety of patients. N Engl J Med. 2002;347:1249-55.

19. Simons SL. Long hours and no breaks: a patient safety concern. Neonatal Netw. 2006;25:445-6.

20. de Carvalho M, Vieira AA. Erro médico em pacientes hospitalizados. J Pediatr (Rio J). 2002;78:261-8.

Correspondence:

Maria Elisabeth Lopes Moreira

Departamento de Neonatologia, Instituto Fernandes Figueira

Av. Rui Barbosa, 716, Flamengo

CEP 22250-020 - Rio de Janeiro, RJ - Brazil

Tel. : +55 (21) 2554.1819

E-mail: bebeth@iff.fiocruz.br 